\title{
Biomedical approaches to care and their influence on point of care nurses: a scoping review
}

\author{
C. Patricia Mazzotta $* 1,2$ \\ ${ }^{1}$ School of Community and Health Studies, Centennial College, Toronto, Canada \\ ${ }^{2}$ School of Nursing, University of Victoria, Victoria, British Columbia, Canada
}

Received: January 7, 2016

DOI: $10.5430 /$ jnep.v6n8p93
Accepted: March 13, 2016

Online Published: April 1, 2016

\begin{abstract}
Nursing in the 21 st century continues to challenge point of care nurses working in high acuity areas. The complexities of patient care are multifaceted, advances in technology, environmental and sociopolitical influences often impede nurse presence at the bedside. Ideally, the intention for these nurses is to broaden their knowledge and ways of knowing beyond the physiological needs of the client, therefore, circumventing biomedical control over their work towards that of a caring science approach. Using Arksey, and O'Malley's five-stage framework, 1) identify the research question, 2) identify relevant studies, 3) study selection, 4) charting the data and 5) collating, summarizing and reporting the results. Eleven papers written in English were selected to examine the research question, "How does the dominance of biomedical approaches to care influence point of care nurses' presence in high acuity areas?" Qualitative software-ATLAS.ti version 7 was used for data collection and analysis; two main themes emerged from the literature: 1) empowered caring, and 2) incommensurable closeness-distance. Future research will need to focus on addressing the challenges acute care nurses face when practicing in high acuity areas heavily influenced by a biomedical approach to care, so that nurses may liberally engage in caring science inclusive of a philosophical worldview and nurse presence regardless of their practice environment.
\end{abstract}

Key Words: Acute care, Biomedical approach to care, Barriers, Caring, Challenges, Scoping review

\section{BACKGROUND}

For centuries, the biomedical model of clinical practice has influenced healthcare; this model continues to be utilized in systematically addressing health concerns in persons who are ill. This model guides physicians' assessment, diagnosis, treatment, critical thinking, and decision making to ensure best patient outcomes. ${ }^{[1]}$ Ultimately, efficient treatment of physiological ailments located within a biomedical model is a common goal for patients admitted to high acuity areas. In order to accomplish this goal, medical and technological paradigms ${ }^{[2]}$ are integrated into the plan of care so that healthcare professionals can describe, anticipate, and predict outcomes based on empirical evidence. ${ }^{[3]}$

The curative focus of a biomedical model continues to influence nurses in practice. Evolving technology, specialized knowledge and advanced skills often have detrimental effects on nurses with some experiencing tensions resulting in nurses question their role at the bedside within a biomedical and technological laden environments. One reason for the angst experienced by nurses is that until the late 1980's nursing education was predominantly influenced by biomedical science-empiricism ${ }^{[4]}$ the emphasis for nursing education

*Correspondence: C. Patricia Mazzotta; Email: pmazzott@uvic.ca; Address: 755 Morningside Avenue, Centennial College, Toronto, Ontario, M1C 4Z4, Canada. Tel: 1416-289-5000 extension 8062,Canada. 
was placed on technical skills, ${ }^{[5]}$ proficiency in assessment, intervention, medical directives and algorithms that guided nursing care ${ }^{[4,6]}$ This does not discount the need for nurses to integrate empirical knowing into their care and decisionmaking, which is a critical component of working in high acuity areas. However, nurses must realize that technology, machines and biomedical interventions can diminish how nurses perceive caring and limit their interactions and connections with patients. ${ }^{[7]}$ As a result, nurses' experience uncertainties when navigating between a biomedical models approach to care and that of the nursing science. Nurses' grapple with integrating theoretical knowledge learned in academic institutions with the realities of clinical practice, often because, contextual factors such as time constraints, patient acuity, and increased workload hinder a nurses' ability to care for patients in a way that brings contentment to their work.

Nurses often find themselves in a conundrum between theory and practice, they appreciate the importance of integrating a biomedical approach to care and technology in practice; however, in reality nurses find themselves overwhelmed by the empirical influence that often overshadows the caring work nurse do. For this reason, nurses working in high acuity areas of practice are confronted with expanding their knowledge and understanding of what it means to nurse in areas where a biomedical model approach to care and technology are prominent, without losing the essence of a nurse presence. Nurses recognise that the relationship between the nurse and patient is of utmost importance. ${ }^{[8]}$ However, the reality is that nurses often fail to establish meaningful connections with their patients because circumstances beyond their control hinder them from doing so. The literature acknowledges that nurses often struggle with time constraints, working understaffed, implementing aggressive medical intervention and sociopolitical factors that hinder nurse presence at the bedside. ${ }^{[9-11]}$ This further hinders a nurse's ability to establish a therapeutic relationship, resulting in nurses distancing themselves, losing physical proximity ${ }^{[12]}$ and nurse presence. ${ }^{[4,13]}$

A biomedical model continues to influence patient care because emphasis is placed on evidence-based practice with measurable outcomes; ultimately, resembling an audit culture with the undertone of a business model. ${ }^{[14-16]}$ Nurses should never be reluctant to integrate a biomedical model or technology into practice because this affords nurses the opportunity to expand critical thinking and problem-solving abilities. Nurses need to incorporate diverse nursing knowledge including technology, equipment, and lifesaving measures as part of wholistic care, ${ }^{[7,17]}$ rather than viewing technology as a hindrance to wholism. Nurses must also learn to explicate the meaning of space and place ${ }^{[18]}$ with each clinical situation encountered they must be willing to embrace different paradigms so that they may achieve the best patient outcomes. A biomedical model and technology can never fully capture the lived experience of what it means to be ill $^{[19]}$ because technology can never replace the closeness and empathy of the human touch. ${ }^{[4,13,19,20]}$ Therefore, to fully understand and integrate wholistic care nurses need to incorporate diverse ${ }^{[3]}$ paradigms as part of their knowledge and decision-making to enhance a therapeutic nurse-patient relationship and nurse presence.

The purpose for undertaking the scoping review was to explore the literature and gain insight on how biomedical and technological paradigms influence acute care nurses in high acuity units. The literature will identify gaps in education, practice, and research in nursing, thus informing future curriculum development, incorporation of workplace education, integration of formal mentorship programs, and enhanced nursing inquiry and knowledge development.

The objective for the scoping review is to examine the research question: "How does the dominance of biomedical approaches to care influence point of care nurses' presence in high acuity areas?" The research question illuminates themes in the literature that are useful in articulating the need for further research and programs to assist point of care nurses practicing in areas influenced by a biomedical model and technological influences. Consequently, nurses face the challenge of blurring the boundaries of competing paradigms (technological, medical, and nursing). A nurse's standpoint must then extend beyond the physiological, technological, and empirical realms towards one of understanding the complexities and interconnectedness of nursing the whole person $^{[21,22]}$ because what nurses know determines what they do. Through the integration of knowledge synthesis and translation $^{[23]}$ nurses use diverse nursing knowledge ${ }^{[24]}$ and nurse presence to guide care and decisions especially when nursing practice is influenced by biomedical, structural and organizational influences. ${ }^{[12,21,25]}$ For this reason, nurses working in high acuity areas need to acknowledge that they cannot adequately care for a patient in a wholistic manner if they fail to recognize that biomedical and technological influences do not hinder nurse presence but rather, supports it.

\section{METHOD}

\subsection{Design}

A scoping review or study is defined as a preliminary assessment of available literature underpinning a specific topic. ${ }^{[26]}$ A 'mapping approach, ${ }^{[26]}$ enables researchers to identify and understand depth and breadth of research evidence while addressing a broad research question. ${ }^{[26-28]}$ According to 
Arksey and O'Malley, ${ }^{[26]}$ there are five steps in their scoping literature framework, consisting of 1) identifying the initial research question; 2) identifying relevant studies; 3) study selection; 4) charting the data and 5) collating, summarizing and reporting the results. This systematic framework enables researchers to identify and examine available literature with depth and breadth. ${ }^{[26,28,29]}$ Therefore, an iterative process of data collection-analysis was utilized to analyze the articles selected based on Arksey and O'Malley's ${ }^{[26]}$ framework.

\subsection{Inclusion/Exclusion criteria}

The sample inclusion criterion for this scoping review was predetermined prior to electronic database searches. Initial collaboration with the Research Librarian at the University of Victoria assisted in determining database research strategies and identification of electronic databases to address the research question "How does the dominance of biomedical approaches to care influence point of care nurses' presence in high acuity areas?" Eligible articles were limited to point of care nurses with a minimum of six months experience working in high acuity areas consisting but not limited to intensive care, emergency department, acute medicine/surgical, outpatient clinics, and palliative care units. Palliative care nurses were included because of the complexity of care, treatment for acute illness, progression of disease process and control of symptoms. ${ }^{[30]}$ All English qualitative, quantitative and grey literature were included in the scoping review ${ }^{[26,31]}$ to explore the extent, depth and breadth of available literature in order to answer the proposed research question. ${ }^{[25]}$ Papers were excluded if they were in a language other than English, if participants were nursing students, educators and if practice settings were long-term care, academic institutions, and non-acute areas.

\subsection{Data selection}

A systematic and methodological search was completed and papers were included if they addressed any aspect of scoping review in relation to a biomedical approach to care, high acuity areas, point of care nurses, challenges and or barriers encountered in a technological laden environment. The following electronic databases were searched: CINHAL, Medline, ERIC, and Google Scholar, with publication limit dates were between January 01, 2004 to November 15, 2015, all countries were included. Database search terms included: "biomedical approach to care", AND "nurse" AND "caring" AND (barriers OR challenges). After initial screening of title and abstracts, 454 papers were retained for further analysis. All papers not meeting the inclusion/exclusion criteria resulted in exclusion from further analysis. This resulted in 131 papers included for further review, these papers were then transferred to Endnote where three duplicate papers were identified and deleted. After completion of level one screening based on title and abstracts/summaries, full review of 67 papers was completed. Level 2 screening of full papers using all identified key words, and relevance to the research question across all databases was carried out and eleven papers were included for final analysis (see Figure 1).

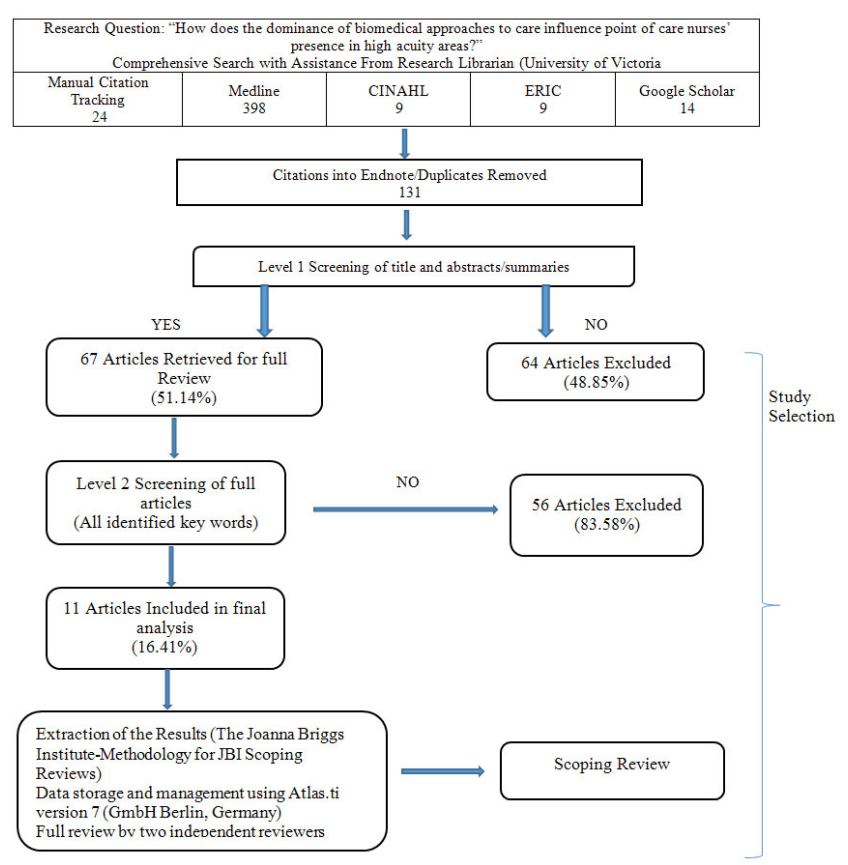

Figure 1. Article Selection Process ${ }^{[32]}$

\subsection{Data collection and analysis}

The Joanna Briggs ${ }^{[33]}$ "extraction of results" [p. 14] format was used to design an extraction excel template in order to document the data. Based on this template, papers were analyzed, and evaluated using a systematic and descriptive approach to determine eligibility of papers in support of purpose, objective, and research question for the scoping review. The identified demographics identified in the retrieved papers were the United States (4), Sweden (3), Ireland (2), Canada (1), and Australia (1). Data extracted from the reports included, but was not limited to author(s), year of publication, country/origin where study was published/conducted, aim/purpose of study, methodology/methods, sample size and population, and key findings related to scoping review question. ${ }^{[26,33]}$

Madden and Condon ${ }^{[34]}$ conducted a quantitative descriptive design on Emergency level 1-Trauma nurses to examine their understanding of family presence during resuscitation. Two narrative qualitative designs, Perry ${ }^{[17]}$ illustrates six palliative care nurses experiences of exemplary care, and Pavlish ${ }^{[35]}$ uses a narrative inquiry to develop a deeper understanding 
of 13 acute care nurses' contextual realities of meaningful moments and conditions that enhance or pose barriers to meaningfulness in nursing. Hov, Hedelin and Athlin ${ }^{[36]}$ use an interpretive phenomenology design of 14 intensive care nurses lived experiences of caring for patients in an Intensive Care Unit (ICU). Udo and colleagues ${ }^{[37]}$ conducted a hermeneutic qualitative study whereby 10 surgical nurses presented critical incidents that were analysed hermeneutically. Two exploratory descriptive studies are included, McCallum and McConigley ${ }^{[38]}$ described provision of end of life care on a high dependency unit for five Registered Nurses, describes the characteristics of a good death as defined by 15 critical care nurses. Bailey and colleagues ${ }^{[39]}$ used a qualitative descriptive design to describe nurses' experiences of delivering spiritual care to palliative care patients. Three articles did not identify a methodology, first, Coffey, Everett and Brown ${ }^{[40]}$ conducted a literature review and case scenario to illustrate the challenges Critical Care/Burn Trauma nurse experiences when caring for a dying patient. Second, Guzetta $^{[41]}$ narrates the trajectory of her career, while explicating previous research studies influencing patient and nurse outcomes in acute care while weaving a body-mind-spirit tapestry. Lastly, Almerud and colleagues ${ }^{[19]}$ use reflection and hyper-reflection to examine two previous phenomenological oriented studies to examine a philosophical point of view in order to understand the dominance of technology for intensive care nurses within an intensive care environment.

All eleven articles were independently analysed and evaluated by two independent reviewers and data was extracted using TJBI excel template. Reviewer one raised a point for discussion in that the Almerud ${ }^{[19]}$ article was not based on original research because the method of reflection-hyperreflection are based on two previously published phenomenological studies. However, after much discussion it was determined that this paper would be included in the scoping review as grey literature because it met the inclusion criteria, purpose, and objective but also, because of its relevance and contribution to scoping review.

The first step undertaken to analyzing all eleven final papers was to code the data. The purpose for coding using line-by-line analysis is to identify recurring words, phrases, concepts within the data to illuminate underlying patterns for further analysis. ${ }^{[42]}$ All articles were read in full, key findings were highlighted and compared with findings from both independent reviewers. Line-by-line coding was completed using ATLAS.ti version 7 Qualitative Software. Making the data manageable and to identify meaningful patterns and groupings ${ }^{[43]}$ within the data. Engaging and reflecting in the data is a long but necessary process. ${ }^{[4]}$ The following nine categories emerged in order of dominant codes: nurse pres- ence (123), knowledge (82), experience (61), environment (57), invaluable use of 'self' (48), technology (45), power relationships (44), sociopolitical factors (41), and time (39). After categorizing data each code was re-evaluated to ensure suitability in each category; this resulted in no changes to codes within the categories. Based on the nine identified categories, theming occurred using identified interconnections, thoughts, memo writing, and process of interweaving and integrating categories together through an iterative process, two themes emerged empowered caring, and incommensurable closeness-distance.

\section{Findings}

Overall, point of care nurses face many challenges and barriers when working on units influenced by a biomedical approach to care. Many of the nurses acknowledged that medical and technological paradigms had control over them in their areas of practice. This contributes to feeling overwhelmed by the acuity and complexity of patients in their care. Advances in technology inadvertently overpower the nurse-patient relationship, thus shifting the focus from a wholistic to reductionist lens. The two themes empowered caring and incommensurable closeness-distance address the research question: "How does the dominance of biomedical approaches to care influence point of care nurses' presence in high acuity areas?"

\subsection{Empowered caring}

Empowered caring emerged from the categories because of the barriers and challenges facing point of care nurses. Regardless of sociopolitical factors such as diminished funding, increased workload, demands on nurses, policies ${ }^{[38]}$ shorter hospital stays ${ }^{[36]}$ and increased technology ${ }^{[40]}$ nurses acknowledge that these factors influence their care and nurse presence. The responsibility lies with the nurse to ensure that when they are engaging with patients, they practice wholistically and do not make decisions based solely on medical or technological influences. Nurses need to overcome a multitude of challenges by grounding themselves within a nursing paradigm that extends beyond the disease process. ${ }^{[17,35,36,40]}$

The literature clearly articulates that nurses had difficulty simultaneously caring for patients who were critically ill and caring for patients whose care was withdrawn because nurses grappled with the shift of care from curative and lifesaving to comfort measures only. ${ }^{[38]}$ Nurses often prioritized patient care based on medical directives and facts ${ }^{[36,40]}$ rather than wholistic care. Thus, nurses were not able to establish meaningful connections with patients. ${ }^{[35,37]}$ Moreover, meaningful connections were hindered because of existing power relationships whereby, divisive management did not 
support nurses' voice when advocating for integration of care focusing on spiritual needs of the patient. ${ }^{[35]}$ Without a doubt when organizational leaders are not supportive of wholistic care, nurses become personally and emotionally involved, hence further adding to nurses' angst. In addition, nurses find themselves in situations where medical interventions are initiated because of medical and technology influence, rather than a wholistic approach. Almerud and colleagues ${ }^{[19]}$ posit that medical advances and technology does not have to hinder patient care, because it is not the technology or equipment that guides nurses actions, rather it is how and what meaning nurses give to the equipment. Nurses have control and the ability to make decisions on how a person is cared for and nurses can choose a wholistic manner or reduce the individual to a mere object.

Despite nurses identifying that they feel overwhelmed by the emotional connections they establish with patients they also admit that the connections are the foundation for meaningful moments, therefore, shifting the focus from disease process or illness, to the patient becoming the center of care. ${ }^{[35]}$ Nurses are then challenged to accept that although technology, medical directives, life-saving protocols, and ag gressive treatment dominates high acuity areas, this does not mean that nurses should continue to accept the tensions and existing dualism between nursing/medicine, subjectivity/objectivity and reductionism/holism in practice settings. ${ }^{[19]}$ Instead, by acknowledging existing tensions and dualisms, nurses are better able to comprehend ways to blur these boundaries. For instance, nurses must remember that they care for the patient in the bed and not the equipment and acknowledge that the equipment does not take precedent over a life. ${ }^{[19]}$ Despite advanced knowledge, skills, and education nurses have acquired, it is necessary to be mindful that technology is a necessary tool to assist in monitoring a patient, ${ }^{[17,19,36,45]}$ and should supplement nursing care not overpower it. The integration of theoretical knowledge, simple gestures carried out with a compassionate heart, ${ }^{[17]}$ hands that touch a person who is suffering, ${ }^{[36]}$ a soft voice that reassures a patient ultimately communicates that nurses are listening while conveying trust, respect and that they care.

Hov and colleagues ${ }^{[36]}$ reported that ICU nurses working in highly technical areas reported that procedures and nursing care was "skillfully performed at a tempo adjusted to the patient's rhythm and with cautious and tender use of nurses' hands" [p. 336]. Practicing using caring science places the nurse in a space and place ${ }^{[18]}$ demonstrating to the patient that care extends beyond empirics. More important, a biomedical approach to care and technology cannot replace nurse presence and empowered caring because patient's individuality, subjectivity and dignity ${ }^{[19]}$ is of utmost importance

Published by Sciedu Press in wholistic care. Nurses are advocates, a voice when their patients cannot speak for themselves, they challenge the status quo when everything seems hopeless, ${ }^{[40,45]}$ even when physicians want to pursue aggressive medical treatment in futile situations. $^{[45]}$

A biomedical model and technology in high acuity areas has the potential to overshadow humanistic caring, making nurses question what is dignified care in high acuity areas. To ensure wholistic care nurses establish communities of practice, collaborative learning environments, and pedagogic strategies that include mindfulness, reflection, and refinement of emotional and spiritual ${ }^{[46]}$ experiences that have the potential to enhance wholistic care. Almerud and colleagues ${ }^{[19]}$ reiterate that when nurses solely focus on equipment, technology and measureable outcomes the nurse becomes an extension of the machine making the patient invisible. Technology "enslaves" ${ }^{[19]}$ (p. 58) the caregiver, giving a false sense of security therefore, nurses should individualize care by assessing the whole patient beyond their physiological needs. The patients' emotional, psychological, spiritual, and cultural needs must be met. ${ }^{[17,39,40,45]}$ This is the essence of what makes nurses unique and a valuable resource when caring for patients. Nurses have the capacity to engage and make meaningful connections with their patients through empowered caring because nurse presence is ultimately, what enables nurses to meet the existential needs of those entrusted in our care.

\subsection{Incommensurable closeness-distance}

Nurses working in the 21 st century are challenged with the incommensurable closeness-distance encountered in their daily work. The integration of lifesaving measures, ${ }^{[39]}$ family presence during cardiopulmonary resuscitation, ${ }^{[34]}$ death with dignity, ${ }^{[17,36,40,45]}$ advanced medical directives, ${ }^{[17,37]}$ and competing paradigms have created tensions for point of care nurses in high acuity areas. These tensions arise when nurses are expected to act in ways that cause conflict. For instance, Madden and Condon ${ }^{[34]}$ report that nurses believe their role included advocating for their patients, however, the reality was that although nurses wanted to bring family members to the bedside during resuscitation, " $58 \%$ believed it would cause conflict with the emergency team" [p. 437]. Although nurses acknowledge the importance of having family presence during resuscitation (being close to their loved one), the nurse did not want to cause tensions amongst the team, thus distancing themselves from doing what was morally and ethically right.

Biomedical approaches to care and technology continue to dominate high acuity areas, the advanced knowledge, education, and skills that nurses possess enable them to care 
efficiently for complex and critically ill patients. However, nurses sometimes become complacent and distance themselves from patients because of the stress of constantly making critical decisions, resulting in nurses performing their work in a robotic manner or that resembling a technician. ${ }^{[19]}$ Patients report that even when they received continuous monitoring in the ICU, it meant nothing to them because they did not feel they were treated as human beings. Nurses admit distancing themselves from their patients because their focus was the equipment and technology and not the person in the bed. ${ }^{[17,39]}$ Closeness is established when nurses use their advanced knowledge, skill and problem solving ability, their decision-making by focusing their care on the whole person. ${ }^{[17]}$

Bratcher ${ }^{[45]}$ reports that ICU nurses demonstrate closeness by not allowing a patient to die alone, their communication is open, compassionate and meaningful connections are shared between nurse and patient. ${ }^{[17,36,37]}$ Thus, suggesting that education and knowledge are key for nurses in establishing closeness with patients. For instance, experienced nurses were deeply satisfied when they advocated openly for patient's wishes, alleviated patient's suffering, pain, and emotional distress. This demonstrated closeness, as they were able to incorporate existential ways of understanding the patient based on the patient's beliefs. ${ }^{[17,36,37]}$ Conversely, novice nurses found it difficult to establish meaningful connections with patients because they felt they did not have the knowledge or comfort level to address existential concerns that were outside of physiological or medically based needs. ${ }^{[34,37]}$ Therefore, novice nurses distance themselves from their patients because of their inability to address their patient's emotional and existential needs. ${ }^{[37]}$ Guzzetta $^{[41]}$ acknowledges that novice nurses do not have enough experience to question a biomedical model approach to care and that the body is not the sole focus of nursing care, because viewing the patient from this standpoint hinders closeness. Whereas, integrating a body-mind-spirit approach enables nurses to use alternative approaches to caring for a patient, thus limiting distance.

Incommensurable closeness-distance is affected by the environment, which is dominated by modern technology. Care is delivered using a biomedical model of care; hence, nurses are challenged in providing wholistic care amidst chaos and havoc, thus affecting the closeness of nurse-patient interactions. An ICU setting is hectic, technology drowns communication, ${ }^{[19]}$ and an increased need to treat life-threatening illnesses requires integration of technological instruments to help nurses monitor patients better. However, this type of environment becomes laden with empirics and technology and although a patient is physically present, they are invisible.
Time is another critical factor that influences incommensurable closeness-distance. Sociopolitical factors such as time constraints, decreased job satisfaction, task focused environment and lack of recognition ${ }^{[35]}$ all contribute to how nurses distancing themselves from their patients. Time constraints and increased workload do not afford nurses the opportunity to nurse beyond the expectations of a dominant biomedical influence. However, if nurses are willing to acknowledge that meaningful work can influence positive change in nursing discourse and culture nurses can begin to build communities of practice and a cohesive team. This may assist in increasing the time spent engaging with patients. ${ }^{[37]}$ Therefore, incommensurable closeness-distance cannot be measured; however, nurses can limit distancing themselves by acknowledging that patients in their care depend on the fluidity of movement and action, the use of touch and nurse presence at the bedside.

\section{DISCUSSION}

The intention for this scoping review was to examine the literature available to address the research question "How does the dominance of biomedical approaches to care influence point of care nurses' presence in high acuity areas?" The importance of addressing this question is that biomedical and technological approaches to care continue to influence how nurses care for patients in the 21 st century. ${ }^{[14,16]}$ The advances in healthcare, integration of medical directives and specialized nursing knowledge and skills place point of care nurses in an optimal position to influence how patients are cared for in high acuity areas. Nurses find themselves grappling between existing tensions especially when a curative, lifesaving approach is the focus despite hopeless clinical situations. ${ }^{[38]}$ However, nurses must acknowledge that biomedical and technology influences provide nurses the opportunity to acquire empirical evidence and knowledge within the healthcare team.

In this review, point of care nurses' concur that nurse presence is vital when practicing in biomedical and technological laden environments, empirics alone cannot overshadow the important work nurses do. In fact, through a collaborative approach and integration of multiple perspectives, a patient's plan of care becomes individualized and a reductionist approach is avoided. ${ }^{[4,13,19]}$ Empowered caring illuminates that without empirical knowing, depth, and breadth of knowledge, critical thinking and advanced skills would not be possible. Technology and equipment are just tools that assist nurses in their work. Constant monitoring of equipment should never provide sense of security, because monitoring the patient, establishing meaningful connections, and intuition should also influence decision-making. ${ }^{[19]}$ A patient will remem- 
ber a gentle touch, the compassion and caring approach, a soft voice, and the manner in which a nurse advocated for them when they did not have a voice. These actions should guide nursing care in conjunction with a biomedical and technological lens.

An incommensurable closeness-distance does influence how nurses' care for a patient by acknowledging their personal biases, knowledge limitations, and comfort level, nurses can begin to address existential needs that patients may have, but also to challenge themselves to see the patient beyond the physiological ailment. ${ }^{[37]}$ Organizational leaders are in positions to influence change within high acuity areas, thus, recognizing the work nurses do, supporting a cohesive team approach to care and addressing the need for wholistic care will support the nurse in enacting meaningful connections with patients and their families.

This scoping review identified several gaps in the literature needing further research. Specifically, nurse educators in academic and organizational institutions need to integrate diverse paradigms into curriculum, and clinical practice so that nurses can comprehend and incorporate a wholistic approach to care. Consequently, this means shifting worldviews and embracing a philosophical approach to care that challenges nurses to critically think and reason ${ }^{[47]}$ thus provides nurses the opportunity to appreciate the relationship between philosophies that underpin nursing practice, but also nursing theories that guide care of the whole person. ${ }^{[48]}$ Philosophical inquiry also encourages nurses to use reflective practice to re-evaluate their nursing philosophies. When nurses incorporate diverse Patterns of Knowing ${ }^{[49]}$ into their work, nurses themselves evolve. ${ }^{[4]}$ Integrating philosophical inquiry into workplace learning, orientation, and formal mentorship programs enables nurses to develop the skills required to enhance and develop discourse, expand theoretical knowledge, allow for examination of assumptions, and develop the ability to critique practice utilizing reasoned arguments. ${ }^{[50]}$ Furthermore, formal mentorship programs need to mentor and educate nurses on how to integrate all Patterns of Knowing, ${ }^{49]}$ nursing theories, and philosophical underpinning into practice. Currently, most orientation provided for nurses commencing work in high acuity areas focus on a biomedical approach to care. For example, nurses are educated and evaluated on medical directives, advanced nursing skills, assessments, algorithms, policies, and procedures. From this educational perspective, the assumption is that when working in high acuity areas, the biomedical and technological paradigms take precedence and the emotional, psychological, and existential needs of the patient are not a priority. The literature suggests that philosophical inquiry enhances a nurses' ability to develop an aptitude for critical thinking, ${ }^{[48,50]}$ formulating arguments for abstract ideas beyond an empirical realm. ${ }^{[50]}$ Therefore, educating nurses and providing continuous mentorship will provide nurses with the opportunity to address practice gaps, improve communication skills, and engage in meaningful connections with patients and their significant others, but also among nurses and with the self.

\section{Conclusion}

Point of care nurses in the 21st century face challenges when competing paradigms influence their care; for this reason, it is imperative that nurses embrace a wholistic standpoint grounded in a philosophical worldview when caring for patients on units that are highly influenced by a biomedical approach to care and technology. By examining the research question "How does the dominance of biomedical approaches to care influence point of care nurses' presence in high acuity areas?" the themes, empowered caring and incommensurable closeness-distance emerged from the data. These themes highlight the need for nursing education, research, and formal mentorship programs. These programs must incorporate all Patterns of Knowing ${ }^{[49]}$ and philosophical inquiry so nurses are better able to ask and answer the question "what is my philosophy of nursing?" Being able to answer this question is vital if nurses are to address the challenges and barriers to caring for patients. Nurses should not resist or reject a biomedical approach to care or technology, rather, nurses should acknowledge the contribution both make towards nursing knowledge and clinical practice.

\section{ACKNOWLEDGeMENTS}

The author acknowledges the assistance provided by Jessica Mussel, BA (Psyc), MLIS, Distance Learning and Research Librarian at the University of Victoria, B.C. Canada and Dr. Lynne Young, RN, PhD. Professor, School of Nursing, University of Victoria, B.C, Canada for her feedback on this manuscript. Edward Vernon Cruz, RN, BN, MEdM, MScN, $\mathrm{PhD}$ (DentSc) and Marsha Astrop, RN, BScN, MScN for their contribution as independent reviewers.

\section{Conflicts of InTERest Disclosure}

The authors declare that there are no competing interests. 


\section{REFERENCES}

[1] D'Antonio P, Fairman J. Organizing practice: nursing, the medical model, and two case studies in historical times. Criminal Behavior Mental Health. 2004; 21(2): 411-429.

[2] Browning AM. Life-support technology and the dying experience: Implications for critical-care nursing practice. Dimensions of Critical Care Nursing. 2010; 29(5): 230-237. PMid:20703130. http: //dx.doi.org/10.1097/DCC.0b013e3181e6c8c1

[3] Grove SK, Gray JR, Burns N. Introduction to nursing research and evidence-based practice. In Understanding nursing research: Building an evidence based practice (6 ed.). St. Louis, MO: Elsevier Saunders; 2015. p. 1-30.

[4] Chan EA. A lived experience of dualism between the natural and human science paradigms in nursing. Issues and Innovations in Nursing Education. 2002; 40(6): 739-746. http://dx.doi.org/10.1046 /j.1365-2648.2002.02433.x

[5] Metcalfe M. Improving the safety of oxygen therapy in the treatment of myocardial infarction. International Emergency Nursing. 2012; 20(2): 94-97. http://dx.doi.org/10.1016/j.ienj . 2011.01. 004

[6] Thompson G, AustinW, Profetto-McGrath J. Novice nurses' first death in critical care. Canadian Association of Critical Nurses. 2010; 21(4): 26-36. PMid: 21226411.

[7] Jakimowicz S, Perry L. A concept analysis of patient-centered nursing in the intensive care unit. Journal of Advanced Nursing. 2015; 71(7): 1499-1517. http://dx.doi.org/10.1111/jan.12644

[8] Doane G, Varcoe C. Relational practice and nursing obligation. Advances in Nursing Science. 2007; 30(3): 192-205. PMid:17703120. http://dx.doi.org/10.1097/01.ANS.0000 286619.31398.fc

[9] Urban AM. Taken for granted: normalizing nurses' work in hospitals. Nursing Inquiry. 2013; 21(1): 69-78. http://dx.doi.org.ezpro xy.library.uvic.ca/10.1111/nin.12033

[10] Myrick F, Young O, Billay D. Preceptorship and practical wisdom: A process of engaging in authentic nursing practice. Nursing Education in Practice. 2010; 10: 82-87. PMid:19442585. http: //dx.doi.org/10.1016/j.nepr.2009.03.018

[11] Van der Zalm JE. Hermeneutic-phenomenology: providing living knowledge for nursing practice. Journal of Advanced Nursing. 2003: 31(1): 211-218. http://dx.doi.org.ezproxy.library.uvic . $\mathrm{ca} / 10.1046 / \mathrm{j} .1365-2648.2000 .01244 . \mathrm{x}$

[12] Delmar C. The excesses of care: A matter of understanding asymmetry of power. Nursing Philosophy. 2012; 13: 236-243. http: //dx.doi.org/10.1111/j.1466-769X.2012.00537.x

[13] Nagel DA, Pomerleau SG, Penner JL. Knowing, caring, and telehealth Technology: "Going the distance" in nursing practice. Journal of Holistic Nursing. 2013; 31(2): 104-112. http://dx.doi .org/1 $0.1186 / 1472-684 \mathrm{X}-13-29$

[14] Austin WJ. The incommensurability of nursing as a practice and the customer service model: an evolutionary threat to the discipline. Nursing Philosophy. 2011; 12: 158-166. PMid:21668615. http://dx.doi.org/10.1111/j.1466-769X.2011.00492.x

[15] Covell CL. The middle-range theory of nursing intellectual capital. Journal of Advanced Nursing. 2008; 63(1): 94-103. http: //dx.doi.org/10.1111/j.1365-2648.2008.04626

[16] Storesund A, McMurray A. Quality of practice in an intensive care unit (ICU): A mini-ethnographic case study. Intensive and Critical Care Nursing. 2009; 25: 120-7. PMid:19307120. http: //dx.doi.org/10.1016/j.iccn.2009.02.001

[17] Perry B. Exemplary care of the palliative patient: The journey shared. The Canadian Association of Critical Care Nurses. 2005; 16(3): 1621.
[18] Jonas-Simpson C. The possibility of changing meaning in light of space and place. Nursing Science Quarterly. 2006; 19(2): 8994. PMid:16624975. http://dx.doi.org/10.1177/089431840 6286828

[19] Almerud S, Alapack RJ, Fridlund B, et al. Beleaguered by technology: Care in technologically intense environments. Nursing Philosophy. 2008; 9: 55-61. PMid:18154637. http://dx.doi.org/10.1111 /j.1466-769X.2007.00332.x

[20] Jasmine T. Art, science, or both? Keeping the care in nursing. Nursing Clinics of North America. 2009; 44: 415-421. PMid:19850178. http://dx.doi.org/10.1016/j.cnur.2009.07.003

[21] Manning-Walsh J, Wagenfeld-Heintz E, Asmus A, et al. Relationshipcentered care: The expanding cup model. International Journal of Human Caring. 2004; 8(2): 26-31.

[22] McEvoy L, Duffy A. Holistic practice-A concept analysis. Nurse Education in Practice. 2008; 8: 412-419. http://dx.doi.org/10. 1016/j.nepr. 2008.02.002

[23] Kastner M, Tricco AC, Soobiah C, et al. What is the most appropriate knowledge synthesis method to conduct a review? Protocol for a scoping review. Medical Research Methodology. 2012; 12(114): 1-10. http://dx.doi .org/10.1186/1471-2288-12-114

[24] Luntley M. What nurses know? Nursing Philosophy. 2011; 12: 22-33. http://dx.doi.org/10.1111/j.1466-769X.2010.00466.x

[25] Gagnon J, Duggleby W. The provision of end-of-life care by medicalsurgical nurses working in acute care: A literature review. Palliative and Supportive Care. 2014; 12: 393-408. http://dx. doi .org/10. $1017 /$ S1478951513000965

[26] Arksey H, O’Malley L. Scoping studies: Towards a methodological framework. International Journal Social Research Methodology. 2005; 8(1): 19-32. http://dx.doi.org/10.1080/13645570320 00119616

[27] Grant MJ, Booth A. A typology of reviews: An analysis of 14 review types and associated methodologies. Health Information and Libraries Journal. 2009; 26: 91-108. http://dx . doi .org/10.11 11/j.1471-1842.2009.00848.x

[28] Levac D, Colquhoun H, O’Brien KK. Scoping studies: Advancing the methodology. Implementation Science. 2010; 5(69): 1-9. http://dx.doi.org/10.1186/1748-5908-5-69

[29] Davis K, Drey N, Gould D. What are scoping studies? A review of the nursing literature. International Journal of Nursing. 2009; 46: 1386-1400. http://dx.doi.org/10.1016/j.ijnurstu. 20 09.02 .010

[30] Krause RS, Talavera F, Setnik G, et al. Palliative care in the acute care setting. E-Journal of Medscape. 2015. Available from: http://emedicine.medscape.com/article/1407757 -overview\#showall

[31] Armstrong R, Hall BJ, Doyle J, et al. Cochrane update 'Scoping the scope' of a Cochrane review. Journal of Public Health. 2011; 33(1): 147-150. http://dx.doi.org/10.1093/pubmed/fdr015

[32] Cruz EV, Felicilda RR, Mazzotta P, et al. A Meta-Synthesis of Academic Bridging Programs' Effect in Internationally Educated Nurses. University of Alberta Education and Research Archive. 2014. Available from: http://hdl. handle.net/10402/era. 38642

[33] The Joanna Briggs Institute. The Joanna Briggs Institute reviewers' manual. Methodology for JBI scoping reviews. 2015. Available from: www . joannabriggs . org

[34] Madden E, Condon C. Emergency nurses' current practices and understanding of family presence during CPR. Journal of Emergency Nursing. 2007; 33(5): 433-9. http://dx.doi.org/10.1016/j · j en.2007.06.024 
[35] Palvish C, Hunt R. An exploratory study about meaningful work in acute care nursing. Nursing Forum. 2012; 47(2): 113-122. http: //dx.doi.org/10.1111/j.1744-6198.2012.00261.x

[36] Hov R, Hedelin B, Athlin E. Good nursing care to ICU patient on the edge of life. Intensive and Critical Care Nursing. 2007; 23: 331-341. http://dx.doi.org/10.1016/j.iccn.2007.03.006

[37] Udo C, Danielson E, Melin-Johansson C. Existential issues among nurses in surgical care-a hermeneutical study of critical incidents. Journal of Advanced Nursing. 2012; 69(3): 5679-5770. http://dx.doi.org.ezproxy.library.uvic.ca $/ 10.1111 / j .1365-2648.2012 .06032 . x$

[38] McCallum A, McConigley R. Nurses' perceptions of caring for dying patients in an open critical care unit: A descriptive exploratory study. International Journal of Palliative Nursing. 2013; 19(1): 25-30. http://dx.doi.org/10.12968/ijpn.2013.19.1.25

[39] Bailey ME, Moran S, Graham MM. Creating a spiritual tapestry: Nurses' experiences of delivering spiritual care to patients in an Irish hospice. International Journal of Palliative Nursing. 2009; 15(1): 4248. http://dx.doi.org/10.12968/ijpn. 2009.15.1.37952

[40] Coffey R, Everett S, Miller S, et al. End of life in the Burn/Trauma unit: A nursing perspective. International Journal of Critical Illness and Injury Science. 2011; 1(2): 129-131. http://dx.doi .org/10 . 4103/2229-5151.84799

[41] Guzzetta C. Critical care research: Weaving a body-mind-spirit tapestry. American Journal of Critical Care. 2004: 13(4): 320-327. PMid:15293585.

[42] Mayan MJ. Data analysis. In Essentials of qualitative inquiry. Walnut Creek, CA: Left Coast Press Inc; 2009. p. 85-99.
[43] ATLAS.ti 7. ATLAS.ti 7 quick tour. 2015. Available from: http: //downloads .atlasti.com/docs/manual/atlasti_v7_man ual_en.pdf?_ga=1.204324368.1816433467.1457733328

[44] Streubert Speziale HJ, Rinaldi Carper D. Designing data generation and management strategies. Qualitative research in nursing. Advancing the humanistic imperative. Philadelphia, PA: Lippincott Williams \& Wilkins; 2007. p. 35-55.

[45] Bratcher JR. How do critical care nurses define a "good death" in the intensive care unit? Critical Care Nurse Quarterly. 2010; 33(1): 88-99. http://dx.doi.org.ezproxy.library.uvic. $\mathrm{ca} / 10.1097 / \mathrm{CNQ}$.0b013e3181c8e2d7

[46] Wald HS, Anthony D, Hutchinson TA, et al. Professional identity formation in medical education for humanistic, resilient physicians: Pedagogic strategies for bridging theory to practice. Academic Journal. 2015; 90(6): 753-760. http://dx. doi .org/10.1097/ACM. 0 000000000000725

[47] Pesut B, Johnson J. Reinstating the 'Queen': Understanding philosophical inquiry in nursing. Journal of Advanced Nursing. 2007; 61(1): 115-121. http://dx.doi.org/10.1111/j.1365-2648. 2007.04493.x

[48] Powers-Jarvis RS. Between nursing, caring, and technology: Being alive is more than having a beating heart. International Journal for Human Caring. 2012; 16(1): 48-53.

[49] Chinn PL, Kramer MK. Knowledge development in nursing. Theory and process (9th ed.). St. Louis, MO: Elsevier Mosby Inc; 2015

[50] Holt J, Clarke D. Philosophy and nursing: A useful transferable skill. Nursing Philosophy. 2000; 1(1): 76-79. http://dx.doi.org/10. $1046 / j .1466-769 x \cdot 2000.00013 . x$ 